\title{
A Influência do Humor na Seleção de Alimentos em Adolescentes de Campinas, ISACamp 2008-2009
}

\section{Natália Bonfante Carceliano (IC), Julicristie M. Oliveira (0).}

\section{Resumo}

Buscou-se identificar a relação entre a busca por certos alimentos e situações de humor em adolescentes. Observou-se associação entre o alto ingestão de alimentos calóricos, baixa ingestão de frutas e hortaliças com estados depressivos.

Palavras Chave: Dieta, Depressão, Neurotransmissores.

\section{Introdução}

A adolescência é um período de intensas mudanças corporais, por isto se dá grande importância ao estado nutricional' ${ }^{1}$. Os alimentos mais saborosos, mais calóricos e palatáveis estão possivelmente ligados com a recompensam emocional. Ou seja, a comida tem sentidos e significados específicos em diferentes fases da vida e por diferentes motivações².

O objetivo do presente estudo foi identificar a relação entre a busca por certos alimentos e situações de humor em adolescentes de Campinas, SP. Foi utilizada a base de dados do ISACamp 2008-2009 e foram selecionadas as variáveis relacionadas à ingestão alimentar (frutas, hortaliças, refrigerante), bem como a gordura total e sacarose total da dieta estimadas pelo recordatório de 24h. Foram utilizadas, também, as variáveis relacionadas ao sentimento de nervosismo e de tristeza, dentre outras.

\section{Resultados e Discussão}

Foi possível observar, a partir da análise dos dados, que a escolha alimentar estava associada às emoções, como pode ser verificado nas tabelas abaixo.

Tabela 1. Distribuição da frequência semanal de ingestão de frutas segundo dificuldade para realizar com satisfação suas tarefas diárias em adolescentes, ISACamp 2008-2009.

\begin{tabular}{|c|c|c|c|c|c|c|c|}
\hline \multirow{2}{*}{$\begin{array}{c}\text { Tem } \\
\text { dificuldade } \\
\text { para } \\
\text { realizar as } \\
\text { tarefas } \\
\end{array}$} & \multicolumn{6}{|c|}{ Ingestäo de frutas em vezes na semana } & \multirow{2}{*}{ TOTAL } \\
\hline & Diariamente & 4 a 6 & 1 a 3 & $<1$ & $\begin{array}{l}<1 \mathrm{x} \\
\text { mês }\end{array}$ & $\begin{array}{c}\text { Sem } \\
\text { resposta }\end{array}$ & \\
\hline NÃO & 114 & 73 & 164 & 21 & 12 & 5 & 389 \\
\hline$\%$ & 29,31 & 18,77 & 42,16 & 5,40 & 3,08 & 1,29 & 100 \\
\hline SIM & 5 & 2 & 12 & 6 & 1 & 1 & 27 \\
\hline $\mathbf{3} \%$ & 18,52 & 7,41 & 44,44 & 22,22 & 3,70 & 3,70 & 100 \\
\hline TOTAL & 119 & 75 & 176 & 27 & 13 & 6 & 416 \\
\hline$\%$ & 28,61 & 18,03 & 42,31 & 6,49 & 3,13 & 1,44 & 100 \\
\hline
\end{tabular}

Tabela 2. Distribuição da frequência semanal de ingestão de refrigerante segundo sentimento de inutilidade em adolescentes, ISACamp 20082009.

\begin{tabular}{|c|c|c|c|c|c|c|c|}
\hline \multirow{2}{*}{$\begin{array}{c}\text { Tem se } \\
\text { sentido } \\
\text { inútil }\end{array}$} & \multicolumn{6}{|c|}{ Ingestão de refrigerante em vezes na semana } & \multirow{2}{*}{ TOTAL } \\
\hline & Diariamente & 4 a 6 & 1 a 3 & $<1$ & $\begin{array}{l}<1 \mathrm{x} \\
\text { mês }\end{array}$ & $\begin{array}{c}\text { Sem } \\
\text { resposta }\end{array}$ & \\
\hline NÃO & 105 & 65 & 159 & 51 & 16 & 12 & 408 \\
\hline$\%$ & 25,74 & 15,93 & 38,97 & 12,50 & 3,92 & 2,94 & 100 \\
\hline SIM & 0 & 2 & 1 & 1 & 2 & 1 & 7 \\
\hline$\%$ & 0 & 28,57 & 14,29 & 14,29 & 28,57 & 14,29 & 100 \\
\hline TOTAL & 105 & 67 & 160 & 52 & 18 & 13 & 415 \\
\hline$\%$ & 25,30 & 16,14 & 38,55 & 12,53 & 4,34 & 3,13 & 100 \\
\hline
\end{tabular}

Tabela 3. Distribuição da frequência semanal de ingestão de verduras e hortaliças cruas segundo frequência maior de choro em adolescentes, ISACamp 2008-2009.

\begin{tabular}{|c|c|c|c|c|c|c|c|}
\hline \multirow{2}{*}{$\begin{array}{c}\text { Tem } \\
\text { sentido } \\
\text { vontade de } \\
\text { chorar }\end{array}$} & \multicolumn{6}{|c|}{$\begin{array}{l}\text { Ingestão de verduras e hortaliças cruas em vezes na } \\
\text { semana }\end{array}$} & \multirow{2}{*}{ TOTAL } \\
\hline & Diariamente & 4 a 6 & 1 a 3 & $<1$ & $\begin{array}{l}<1 \mathrm{x} \\
\text { mês }\end{array}$ & $\begin{array}{c}\text { Sem } \\
\text { resposta }\end{array}$ & \\
\hline NÃO & 142 & 81 & 109 & 25 & 2 & 19 & 385 \\
\hline$\%$ & 36,88 & 21,04 & 28,31 & 6,49 & 2,34 & 4,94 & 100 \\
\hline SIM & 14 & 8 & 2 & 5 & 1 & 1 & 31 \\
\hline$\%$ & 45,16 & 25,81 & 6,45 & 16,13 & 3,23 & 3,23 & 100 \\
\hline TOTAL & 156 & 89 & 111 & 30 & 10 & 20 & 416 \\
\hline$\%$ & 37,50 & 21,39 & 26,68 & 7,21 & 2,40 & 4,81 & 100 \\
\hline
\end{tabular}

\section{Conclusões}

Conclui-se que o estado emocional pode influenciar a dieta, caracterizando-se por reduzida ingestão de alimentos ricos nutricionalmente e alta ingestão de alimentos calóricos.

\section{Agradecimentos}

\section{SAE Unicamp.}

'SILVA, Julyana Gall da; TEIXEIRA, Maria Luiza de Oliveira; FERREIRA, Márcia de Assunção. Alimentação e saúde: sentidos atribuídos por adolescentes. Esc. Anna Nery, Rio de Janeiro , v. 16, n. 1, Mar. 2012 . Available from <http://www.scielo.br/scielo.php?script=sci_arttext\&pid=S141481452012000100012\&lng=en\&nrm=iso >. Acesso em 10 Set. 2014. 2BOGGIANO, Mary; BURGESS, Emilee.; TURAN, Bulent. Motives for eating tasty foods associated with binge-eating. Results from a student and a weight-loss seeking population. Disponível

em: <http://www.sciencedirect.com/science/article/pii/S01956663140042 31>. Acesso em: 23 out. 2014.. 